\title{
NUEVOS DATOS BIOESTRATIGRÁFICOS Y SEDIMENTOLÓGICOS SOBRE EL ORIGEN DEL COMPLEJO BÁSICO DE QUEPOS, COSTA RICA
}

\author{
Angela Bolz \& Claudio Calvo \\ Anna-Peters-Str. 51/C, 70597 Stuttgart, Alemania \\ E-mail: angelabolz@t-online.de
}

\begin{abstract}
This paper reports the discovery of six species of Late Cretaceous planktic foraminifera in early Paleocene hemipelagic limestones and tuffites from the Quepos promontory of Costa Rica as well as new Paleocene basement exposures in fila Chonta and Parrita indicating the extension of the basaltic basement complex to the northern hinterland area. The foraminiferal assemblage identified is composed of reworked keeled individuals of the species Rosita sp., Globotruncana f. arca (Cushman), Globotruncana cf. ventricosa (White), Globotruncana cf. linneiana (d'Orbigny), Globotruncanella sp., and Gansserina gansseri (Bolli). Of particular biostratigraphic significance is the presence of G. gansseri, a key species from the late Maastrichtian, in three localities studied, because it records in fact older hemipelagic strata within the Quepos Complex, suggesting that the exposed early Paleocene basement rocks probably represent its youngest suite. In the study area, the basement rock assemblage records an emergent edifice -a basaltic island- derived from submarine volcanic activity during the early Paleocene and probably Maastrichtian time. In the absence of evidence for accretion processes related to basement emplacement in this area, both the Cretaceous foraminiferal assemblage and the new Paleocene basement exposures suggest an in-situ origin of the Quepos Basic Complex in the Costa Rican forearc.
\end{abstract}

RESUMEN: Se presenta el hallazgo de seis especies de foraminíferos planctónicos del Cretácico Tardío en calizas y tobitas hemipelágicas danianas del Complejo Básico de Quepos así como nuevos afloramientos del basamento del Paleoceno temprano al norte y noroeste de Quepos, en fila Chonta y Parrita. La asociación de foraminíferos está compuesta de formas cretácicas resedimentadas con quilla de las especies Rosita sp., Globotruncana f. arca (Cushman), Globotruncana cf. ventricosa (White), Globotruncana cf. linneiana (d'Orbigny), Globotruncanella sp. y Gansserina gansseri (Bolli). La presencia de G. gansseri, una especie guía del Maastrichtiano tardío, en tres localidades es de particular importancia bioestratigráfica, ya que señala la probable existencia de rocas cretácicas en los niveles inferiores inmediatos del Complejo de Quepos, sugieriendo que las rocas danianas expuestas representan la unidad más joven del basamento. En conjunto, las secuencias del basamento de Quepos, fila Chonta y Parrita forman parte del flanco de un aparato volcánico emergente -una isla volcánica-, producto de actividad basáltica en la región antearco de Costa Rica durante el Paleoceno temprano y probablemente Maastrichtiano. Considerando la ausencia de estructuras de acreción en el basamento, tanto la asociación de foraminíferos cretácicos como los nuevos afloramientos paleocenos del basamento sugieren una formación in situ del Complejo de Quepos en la región antearco de Costa Rica. 


\section{INTRODUCCIÓN}

El carácter geoquímico y sobretodo la edad paleocena de las rocas del Complejo de Quepos son los criterios distintivos utilizados convencionalmente para separarlo del resto de la secuencia ofiolítica cretácica de Costa Rica e interpretarlo como un complejo acrecionado (Dengo, 1985; Meschede \& Frisch, 1994; Sinton et al., 1997) -a pesar de la ausencia de estructuras de acreción en esa región. En este estudio presentamos el hallazgo de una asociación de foraminíferos planctónicos del Cretácico que constituye un indicio concreto de la probable existencia de rocas cretácicas en niveles estratigráficamente inferiores del Complejo Básico de Quepos. Los objetivos principales son describir cuatro nuevos afloramientos de calizas y tobitas hemipelágicas danianas, y determinar en detalle las especies de foraminíferos cretácicos descubiertas en tres de ellos así como analizar su significado estratigráfico para la interpretación del origen y edad del Complejo de Quepos. Con base en nuevos afloramientos paleocenos del basamento, que se datan por vez primera, demostramos además la extensión del Complejo de Quepos hacia el área del río Cañas, al pie de la fila Chonta y quebrada Palma situada al norte de Parrita.

\section{Marco tectónico}

Las rocas ofiolíticas que afloran a lo largo de la costa Pacífica de Costa Rica forman parte del basamento antearco de América Central, situado en la margen occidental de la placa Caribe (Fig. 1A). La zona de estudio comprende el promontorio costero de Quepos y la zona montañosa del retropaís de fila Chonta y Parrita situada al norte y noroeste de ese promontorio, respectivamente (Fig. 1B-C). En este sector afloran rocas del basamento que se atribuyen al Complejo de Quepos. Estudios geofísicos de sísmica de reflexión en esta región señalan la continuación submarina del basamento de Quepos y su cobertura sedimentaria hacia la plataforma continental (Barboza \& Zucchi, 1994), alcanzando hasta el talud medio, sin in- dicio alguno de estructuras antiguas de acreción (Hinz et al., 1996). La subducción reciente al frente de Quepos está marcada por un pequeño prisma de acreción y en particular por el plateau de Quepos (Fig. 1A), el cual subduce produciendo una fuerte deformación al pie del talud interno de la fosa Mesoamericana (Hinz et al., 1996).

\section{Complejo de Quepos}

Las rocas del complejo básico expuestas a lo largo de la costa del promontorio de Quepos forman una secuencia paleocena de lavas y brechas basálticas, calizas hemipelágicas y materiales piroclásticos (tobitas). La edad paleocena temprana de esta secuencia ha sido determinada a partir de las asociaciones de foraminíferos planctónicos de las calizas hemipelágicas (Azéma et al., 1979; Schmidt-Effing, 1979) y de una datación radiométrica de $64 \mathrm{Ma}$ de un basalto con el método de Ar40-Ar39 (Sinton et al., 1997). Geoquímicamente se trata de basaltos alcalinos de textura vesicular (Wildberg, 1984; Meschede \& Frisch, 1994; Sinton et al., 1997). Los basaltos forman flujos masivos, en almohadilla y en menor grado prismáticos. Texturas vesiculares, compuestas por vesiculas parcialmente rellenas con minerales de zeolita, son comunes en las lavas y en los clastos de las brechas basálticas. Litoestratigráficamente, Baumgartner et al. (1984) agrupan las brechas basálticas en la Formación Brecha Puerto Carrillo y las calizas en la Formación Caliza Pelágica Golfito. En las brechas basálticas de punta Quepos, Azéma et al. (1979) determinaron previamente clastos de calizas con Pseudorbitoides sp. y Sulcoperculina sp., macroforaminíferos típicos del Cretácico tardío, que sugieren la existencia de áreas neríticas cretácicas de procedencia.

\section{MATERIALES Y MÉTODOS}

Realizamos un estudio sedimentológico y bioestratigráfico sistemático de los materiales sedimentarios hemipelágicos intercalados en las 
rocas basálticas (lavas y brechas) del promontorio de Quepos y del área del río Cañas (fila Chonta) (Fig. 2). En particular, el estudio bioestratigráfico se basa en determinaciones micropaleontológicas de las asociaciones de foraminíferos planctónicos. Del total de muestras recolectadas, analizamos 9 muestras de calizas y tobitas en detalle. Las determinaciones micropaleontológicas y microfaciales se llevaron a cabo en sección delgada en formato $4,9 \times 4,9 \mathrm{~cm}$ exclusivamente.
Parte de las observaciones se presentan en las figuras 3, 4 y 5 . Estratigráficamente todos los depósitos estudiados se localizan en el techo de la secuencia paleocena del basamento, muy cerca del contacto superior de ésta con la cobertura sedimentaria suprayacente (Fig. 2). Por último, se incluyen también las observaciones y determinaciones realizadas fuera de la zona de estudio en el área de quebrada Palma, al norte de Parrita (Fig. 1B).

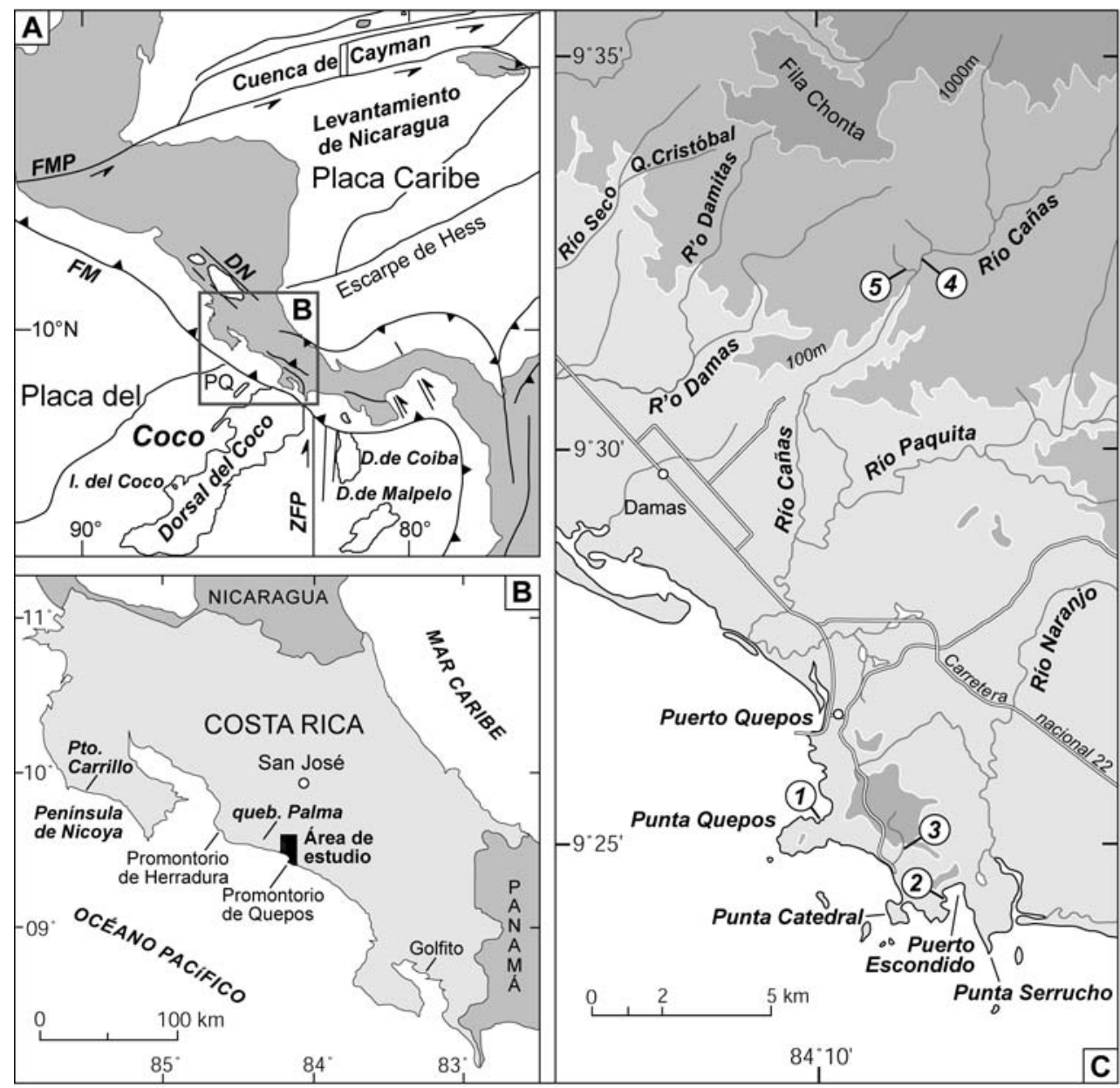

Fig. 1: Ubicación tectónica y geográfica de la zona de estudio - A: mapa tectónico regional de América Central (FMP: falla de Motagua-Polochic; FM: fosa Mesoamericana; DN: depresión de Nicaragua; PQ: plateau de Quepos; ZFP: zona de fractura de Panamá); B: mapa de Costa Rica mostrando el rectángulo del área de estudio (C) y las localidades del litoral Pacífico mencionadas en el texto; C: mapa de detalle del área de estudio comprendiendo el promontorio de Quepos y la fila Chonta; incluye la ubicación de las cinco secuencias de roca estudiadas de la figura 3. 


\section{RESULTADOS}

En la zona del promontorio de Quepos (Fig. 1C) se describen cuatro nuevos afloramientos de calizas y tobitas del Paleoceno Inferior intercaladas en lavas y brechas basálticas del Complejo Básico de Quepos (Fig. 2). En los tres afloramientos de los acantilados costeros de punta
Quepos y puerto Escondido se descubrió una fauna de foraminíferos planctónicos del Cretácico tardío que estudiamos en detalle. En el área del río Cañas (fila Chonta) y en la quebrada Palma, al norte de Parrita se estudian además nuevos afloramientos de rocas basálticas del Paleoceno temprano que son correlacionables con el Complejo Básico de Quepos.

\section{PROMONTORIO DE QUEPOS}

(2)

(1)

Punta Quepos (costa noroeste)

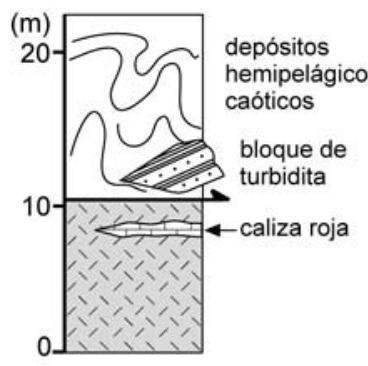

(4)

Río Cañas (cauce medio)

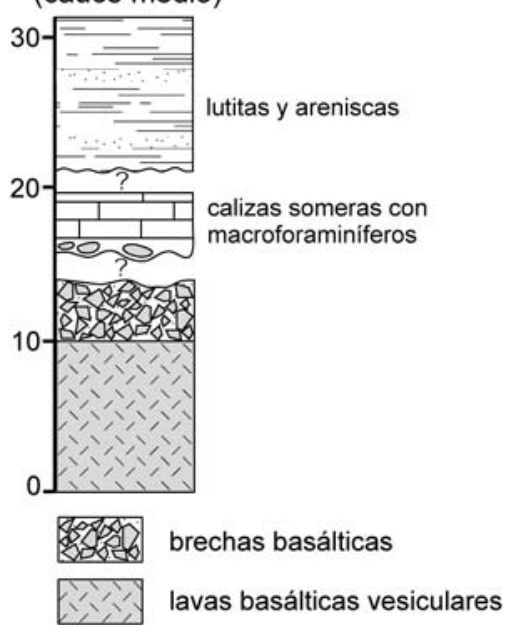

FILACHONTA
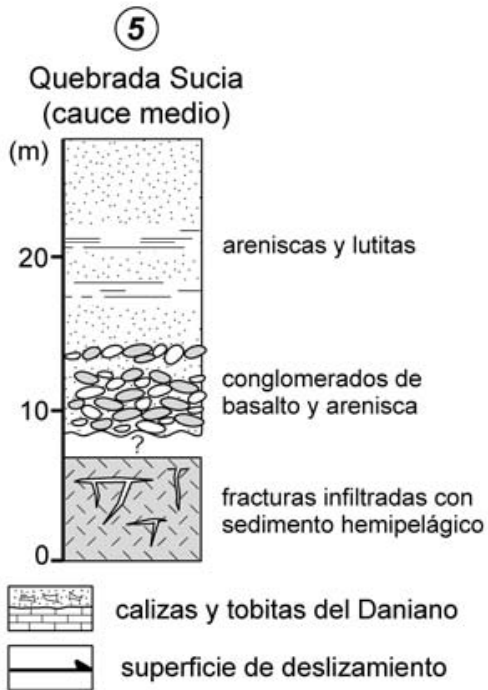

Fig. 2: Secuencias estudiadas del basamento y su cobertura sedimentaria en la región del promontorio de Quepos (1-3) y flanco sur de la fila Chonta (4 y 5). La ubicación correspondiente de las secuencias se encuentra en la figura 1C. Litología de las secuencias 4 y 5 de acuerdo con Becker (1991); edades de las calizas según Calvo \& Bolz (1991). Nótese la posición estratigráfica de las rocas analizadas cerca del contacto con la cobertura sedimentaria, la cual sugiere que éstas forman parte del techo del Complejo Básico de Quepos. 


\section{Afloramientos y litofacies en el promontorio de Quepos}

\section{Calizas rojas de punta Quepos}

Estas calizas afloran en los acantilados de una pequeña ensenada situada en la costa noroeste de punta Quepos (Fig. 1C). Se trata de un cuerpo irregular y muy fracturado de calizas rojizas de pocos centímetros de espesor, que aparece intercalado en una secuencia de lavas basálticas (Fig. 2). Microfacialmente las calizas corresponden a wackestones y en menor grado a packstones compuestos de foraminíferos $\mathrm{y}$ una matriz micrítica rojiza, rica en hidróxidos de hierro. Además contienen fragmentos accesorios de basalto y granos verdes de arcillas autigénicas así como microlitos de plagioclasa. El empaquetamiento de las conchas es muy fuerte, encontrándose con frecuencia contactos suturados. Fracturas rellenas con minerales de calcita son comunes. En este acantilado las rocas del complejo básico están sobreyacidas discordantemente por las calizas hemipelágicas eocenas muy deformadas de la Formación Caótica Punta Quepos, las cuales contienen bloques de turbiditas (Fig. 2).

\section{Calizas y tobitas de puerto Escondido}

La secuencia del complejo básico que estudiamos, aflora en una pequeña punta rocosa, que delimita una pequeña ensenada al lado oeste de puerto Escondido (Fig. 1C). En los acantilados de la parte sur de esa ensenada, Baumgartner et al. (1984) identificaron una secuencia similar con calizas rosadas del Daniano. En el lado noreste de la punta propiamente dicha, se observa una serie de lavas basálticas sobreyacidas por calizas hemipelágicas de color café, brechas basálticas y depósitos piroclásticos (Fig. 2). Microfacialmente, las calizas corresponden a packstones compuestos de foraminíferos planctónicos, matriz micrítica y partículas volcánicas: microlitos de plagioclasa y taquilitas (vidrio volcánico opaco). Entre los foraminíferos se encuentran formas cretácicas con quilla (Fig. 3B).
Los materiales piroclásticos afloran directamente al final del sendero que conduce a la bahía de puerto Escondido, a pocos metros de distancia del afloramiento anterior. Son tobitas vítreas que se alternan con brechas volcaniclásticas de grano fino. Las tobitas muestran una clara laminación paralela marcada por la alternancia de niveles ricos, ya sea en fragmentos de vidrio, arcillas rojizas o minerales autigénicos verdes. Las tobitas están compuestas de fragmentos vesiculares y esquirlas de paredes de vesículas de vidrio volcánico, cristales parcialmente corroídos de plagioclasa y piroxeno, y foraminíferos planctónicos (Fig. 3C). Los foraminíferos se concentran en los niveles arcillosos rojizos (Fig. 3D). El vidrio tiene un ligero color rojizo por causa de las impurezas de óxidos de hierro. Algunos fragmentos muestran bordes incoloros alterados a minerales del grupo de las zeolitas. El tamaño de grano generalmente no sobrepasa $0,25 \mathrm{~mm}$, con excepción de los cristales de piroxeno que alcanzan hasta $0,4 \mathrm{~mm}$ de diámetro.

Las rocas del basamento están sobreyacidas aquí también por depósitos de la Formación Caótica Punta Quepos (Fig. 2).

\section{Calizas de quebrada Camaronera}

En el cauce medio de la quebrada Camaronera, aproximadamente a la altura de $20 \mathrm{~m}$, se encuentra un pequeño afloramiento de basaltos y calizas hemipelágicas, característico del Complejo Básico de Quepos. Las calizas forman un lente de aproximadamente $10 \mathrm{~cm}$ de espesor que se intercala en las lavas. Se trata de calizas de color rosa y beige, ligeramente laminadas. Microfacialmente corresponden a biomicritas con numerosos foraminíferos planctónicos (Fig. $3 \mathrm{~A})$. Unos pocos metros aguas arriba de la quebrada aflora una secuencia turbidítica bien estratificada y con gradación positiva que probablemente sobreyace estas rocas del complejo básico. La presencia de clastos de basalto de 1-3 mm de diámetro en las areniscas turbidíticas gruesas sugiere un contacto sedimentario erosivo entre ambas unidades. 


\section{Asociaciones de foraminíferos}

La fauna de foraminíferos planctónicos de las calizas de punta Quepos está compuesta predominantemente de formas pequeñas y globulares, típicas del Paleoceno temprano; por lo que destacan con facilidad las formas mucho más grandes con quilla del Cretácico tardío. Estas últimas representan con claridad una fauna alóctona, resedimentada. Entre las formas cretácicas de foraminíferos se identificaron en sección delgada tres especies: Rosita sp., Gansserina gansseri (Bolli) y Globotruncana sp. (Fig. 4).
De forma similar, en puerto Escondido la asociación de foraminíferos está constituida principalmente por formas globulares pequeñas del Paleoceno temprano, y formas cretácicas accesorias con quilla (Fig. 3B). En comparación con las calizas de punta Quepos, la fauna en las calizas de puerto Escondido está mejor preservada y es mucho más diversa. Tanto las calizas como las tobitas contienen especies de foraminíferos cretácicos (Fig. 3D y Fig. 4). En las calizas se identificaron Globotruncana f. arca (Cushman), Globotruncana f. linneiana (d'Orbigny), Globotruncana f. ventricosa (White) y
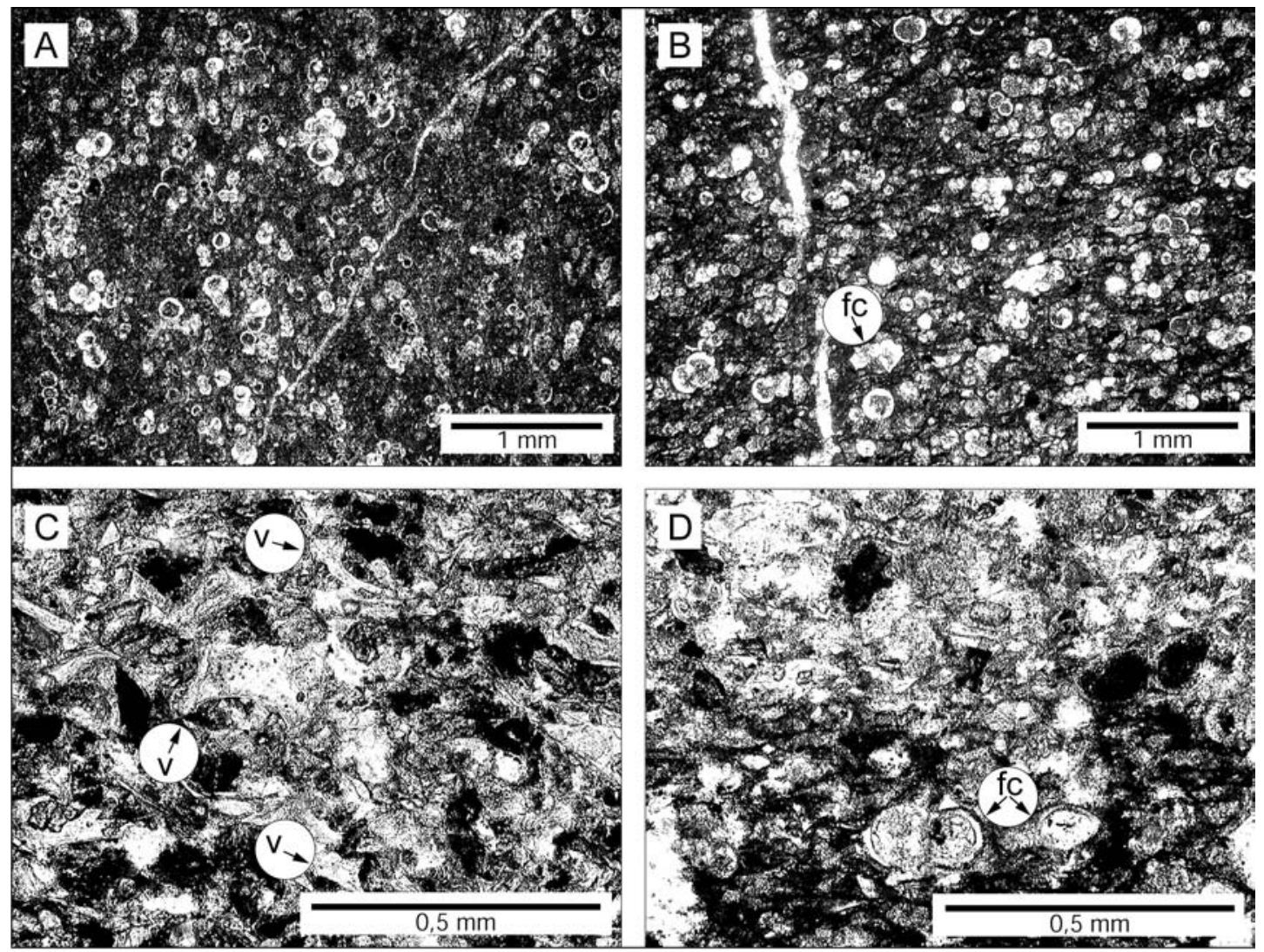

Fig. 3: Microfacies de calizas y tobitas hemipelágicas del Complejo Básico de Quepos - A: wackestone con foraminíferos planctónicos pequeños del Daniano, caliza rosada de quebrada Camaronera, muestra AB-5/3; B: wackestone con foramíníferos del Paleoceno y formas retrabajadas del Cretácico (fc), caliza de puerto Escondido, muestra AB-1/5; C: tobita vítrea de puerto Escondido compuesta de esquirlas de vidrio volcánico (v: fragmentos de paredes de vesiculas), muestra AB-1/6; D: detalle de una tobita mostrando foraminíferos planctónicos cretácicos (fc) en los niveles arcillosos, puerto Escondido, muestra AB-1/6. 

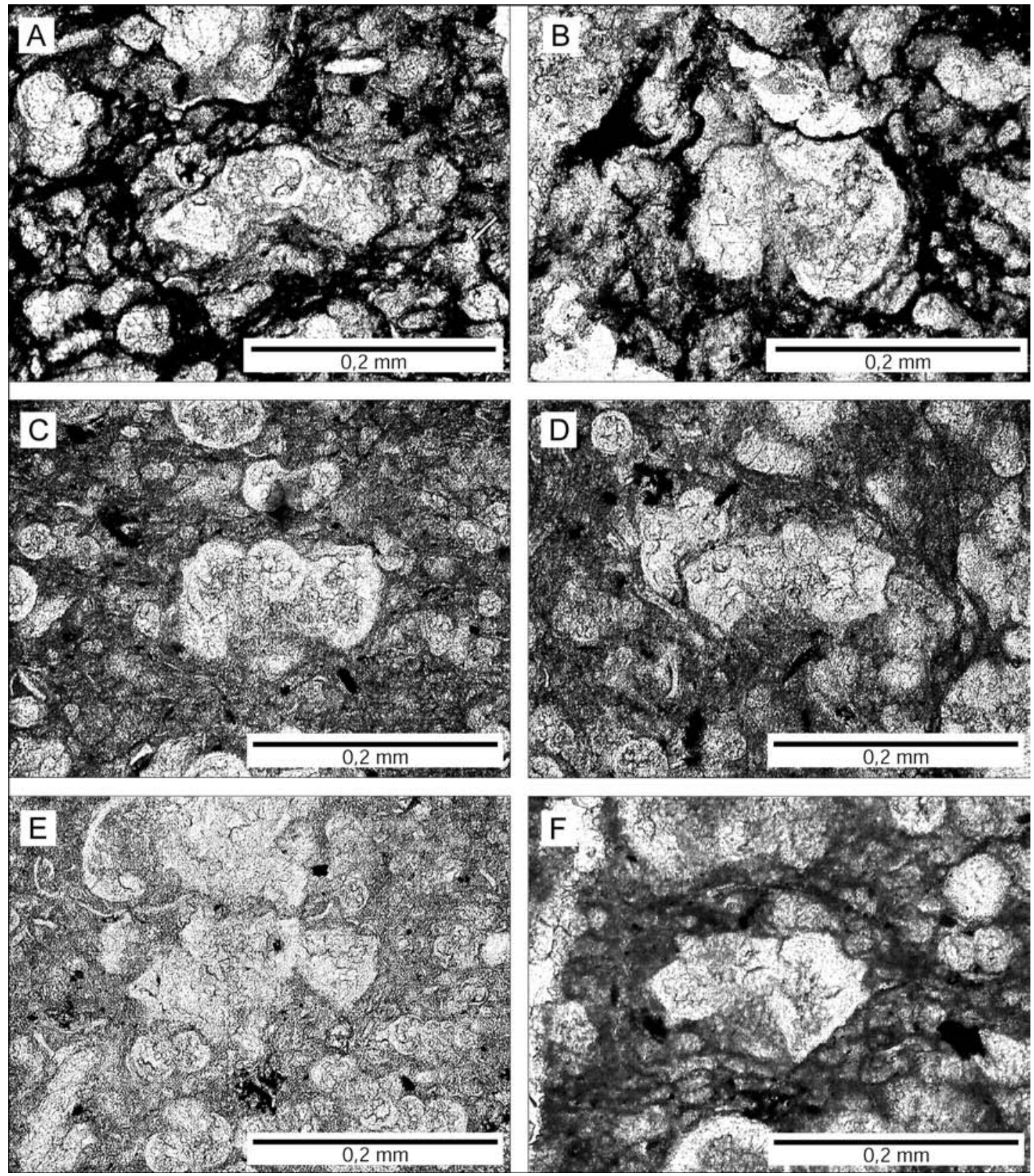

Fig. 4: Foraminíferos planctónicos del Cretácico tardío identificados en calizas hemipelágicas del Complejo Básico de Quepos - A: Rosita sp., caliza roja incluída en lavas basálticas, costa noroeste de punta Quepos, muestra AB-3/2; B: Gansserina gansseri (Bolli), caliza roja incluída en lavas basálticas, costa noroeste de punta Quepos, muestra AB-3/2; C: Gansserina gansseri (Bo1li) en caliza de puerto Escondido, muestra AB-1/5; D: Globotruncana f. linneiana (d'Orbigny), caliza intercalada en brechas basálticas, puerto Escondido, muestra AB-1/5; E: Globotruncana f. arca (Cushman), caliza intercalada en brechas basálticas, puerto Escondido, muestra AB-1/5; F: Globotruncana f. ventricosa (White), caliza de puerto Escondido, muestra AB-1/5. 
Gansserina gansseri (Bolli); mientras que en las tobitas aparecen Globotruncanita sp., Globotruncanella sp. y Gansserina gansseri (Bolli).

A diferencia de las calizas y tobitas de los afloramientos anteriores, la fauna de foraminíferos de las calizas de quebrada Camaronera está constituida exclusivamente de formas trocoidespirales, pequeñas y globulares de pared delgada, típicas del Paleoceno temprano (Fig. 3A). Entre ellas se encuentran ejemplares de la especie $\mathrm{Mo}$ rozovella f. pseudobulloides (Plummer). No se observan formas cretácicas.

\section{Afloramientos y litofacies en el área del río Cañas}

En el flanco sureste de fila Chonta, específicamente en el cauce del río Cañas y su afluente quebrada Sucia aflora una secuencia de rocas basálticas que se puede correlacionar litoestratigráficamente con el Complejo Básico de Quepos que aflora $15 \mathrm{~km}$ más al sur, a lo largo de la costa (Fig. 1C). Esta secuencia está cortada por numerosas fallas y sobreyacida discordantemente por calizas con macroforaminíferos del Paleoceno tardío y sedimentos clásticos de edad desconocida (Becker, 1991; Calvo \& Bolz, 1991).

\section{Río Cañas}

La secuencia estudiada aflora en el cauce medio del río Cañas entre las desembocaduras de dos quebradas afluentes, quebrada Sucia y la quebrada vecina sin nombre situada más al norte (Fig. 1C). Por causa de fallas paralelas con rumbo NW-SE, los afloramientos se repiten y los contactos entre las diferentes litologías son en su mayoría por falla, de modo tal que no se puede reconocer la secuencia estratigráfica continua. La figura 2 muestra una sección representativa que se inicia con lavas basálticas fracturadas, que se caracterizan por su textura vesicular. Hacia el techo están sobreyacidas por brechas basálticas monomícticas. El paso entre ambas litologías parece ser en algunos casos transicional. Las brechas tienen un soporte de grano y se componen de fragmentos angulares de basalto vesicular cuyo diámetro oscila entre 1 y $10 \mathrm{~cm}$. Las rocas basálticas están sobreyacidas por calizas neríticas de la biofacies de Ranikothalia bermudezi del Paleoceno tardío (Calvo \& Bolz, 1991) y lutitas pobremente estratificadas con intercalaciones de areniscas finas de edad desconocida (Becker, 1991) (Fig. 2). La presencia de cantos redondeados de basalto de 3 a $10 \mathrm{~cm}$ de diámetro a la base de las calizas (Becker, 1991) indica un contacto discordante con las rocas basálticas infrayacentes.

\section{Quebrada Sucia}

A diferencia de las lavas anteriores, las lavas de quebrada Sucia, en particular los basaltos vesiculares que afloran en el cauce medio, exhiben una serie de fracturas infiltradas con sedimento hemipelágico de color rosa y rojizo. Microfacialmente, corresponde a sedimento biomicrítico con foraminíferos planctónicos pequeños y globulares de pared delgada, una facies muy similar a la de las calizas del Complejo Básico de Quepos antes descritas. Entre las especies identificadas destacan Morozovella cf. pseudobulloides (Plummer) y Planorotalites f. compressa (Plummer). Esta facies es de suma importancia ya que permite determinar la edad daniana del basamento en este sector y por ende correlacionarlo con el de Quepos. Las rocas basálticas en la quebrada Sucia están sobreyacidas discordantemente por una secuencia clástica que se inicia con conglomerados gruesos de basalto y arenisca, seguidos de una serie de areniscas finas y lutitas (Fig. 2). Según Becker (1991) se trata probablemente de una secuencia de abanico deltáico, sin embargo se desconoce aún su edad.

\section{Infiltraciones sedimentarias en Basalto}

Los basaltos de quebrada Sucia se caracterizan por su textura afanítica, vesicular, y en particular por una serie de fracturas infiltradas con sedimento hemipelágico que analizamos en detalle. Petrográficamente, la textura vesicular hasta amigdaloide se compone de vesiculas generalmente 
irregulares y multiples de pocos milímetros de diámetro (Fig. 5). Las cavidades vesiculares están rellenas con minerales autigénicos de calcita y zeolita, ocasionalmente contienen también sedimento hemipelágico. Las fracturas son muy irregulares alcanzando en la mayoría de los casos varios centímetros de longitud y pocos milímetros de ancho (Fig. 5). En algunas de las fracturas analizadas petrográficamente se reconocen contactos metamórficos entre basalto y sedimento, similares a los descritos por Gursky (1989) en muestras de punta Quepos. En detalle, la zona de metamorfismo de contacto es transicional, empieza con recristalizaciones compuestas de cristales de calcita con textura radial fibrosa que se disponen de forma perpendicular a las paredes de las fracturas. En algunos casos los cristales tapizan casi por completo las paredes de las fracturas. Hacia el interior de la fractura pasan lateralmente a zonas menos recristalizadas de color rosa donde aparecen relictos de sedimento micrítico original, para continuar finalmente a zonas con sedimento hemipelágico inalterado de color rojizo, el cual contiene conchas de foraminíferos planctónicos bien preservadas. El

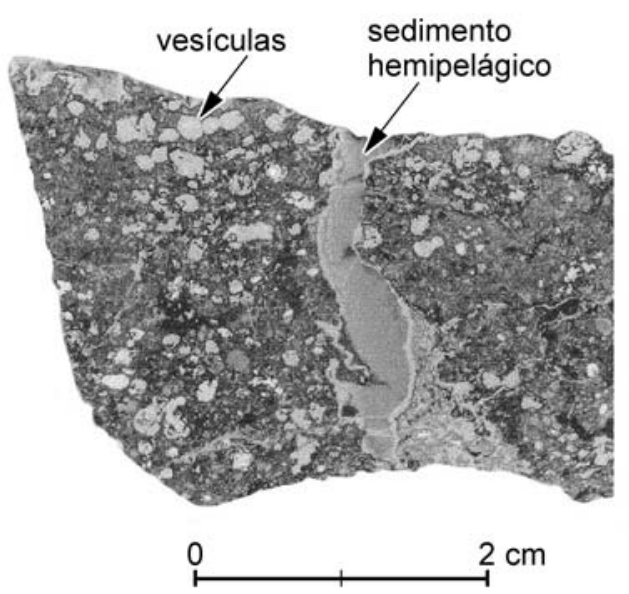

Fig. 5: Basalto vesicular de quebrada Sucia en sección delgada exhibiendo fracturas y vesiculas infiltradas con sedimento hemipelágico y minerales secundarios de calcita y zeolita. El sedimento contiene foraminíferos planctónicos del Daniano, muestra QS-2. color rojizo es por causa del alto contenido de hidróxidos de hierro. Este tipo de metamorfismo de contacto indica que el sedimento hemipelágico penetró rápidamente en fracturas que alcanzaban los niveles interiores aún calientes de las lavas. El origen de las fracturas en sí, podría estar relacionado con la fuerte contracción térmica que experimenta la lava durante la extrusión, al entrar en contacto con el agua marina. Se trata del mismo mecanismo que dió origen a brechas basálticas, que cubren en muchos casos los flujos de lava en almohadilla.

\section{Observaciones en quebrada Palma, Parrita}

Otra secuencia importante del basamento que logramos datar aflora aproximadamente $15 \mathrm{~km}$ al oeste del área de estudio, en la quebrada Palma situada al norte de la ciudad de Parrita (Fig. 1B). La secuencia básica en este sitio, descrita originalmente por Becker (1991), contiene infiltraciones y niveles de calizas hemipelágicas asociadas con rocas basálticas. De acuerdo con nuestras observaciones está constituída litológicamente por lavas y brechas basálticas y en menor grado por sedimentos hemipelágicos finos y tobas palagoníticas vesiculares. Los basaltos y clastos de las brechas basálticas exhiben una textura vesicular. Becker (1991) describe también brechas basálticas con bloques de calizas hemipelágicas de hasta $1 \mathrm{~m}$ de espesor. El espectro de microfacies hemipelágicas es mucho más amplio que en las otras secuencias estudiadas e incluye calizas rojizas con foraminíferos, calizas rojizas con pocos radiolarios únicamente y calizas grises así como lutitas y tobitas finas ricas en materia orgánica. Nuestro estudio se concentra en las infiltraciones sedimentarias centimétricas de las rocas basálticas y en las calizas rojizas que aparentemente sobreyacen por medio de un contacto muy irregular los basaltos en el cauce medio de la quebrada (Becker, 1991). Al igual que en el área de estudio del río Cañas, en quebrada Palma las calizas muestran ocasionalmente contactos metamórficos. En algunos niveles cerca del contacto con los basaltos, las calizas contienen 
inclusiones de fragmentos de basalto vesicular, mostrando contactos metamórficos. Estos fragmentos sugieren que los flujos basálticos probablemente intruyeron un sustrato parcialmente cubierto de sedimento hemipelágico inconsolidado.

\section{Asociaciones de foraminíferos}

El análisis micropaleontológico revela que las infiltraciones sedimentarias en las rocas basálticas y las calizas en contacto con los basaltos de quebrada Palma contienen una fauna de foraminíferos planctónicos, generalmente constituída por formas relativamente pequeñas y globulares. Entre las especies de interés bioestratigráfico se identificaron de nuevo ejemplares bien preservados de los grupos de Morozovella cf. pseudobulloides (Plummer) y Globigerina cf. triloculinoides (Plummer) del Paleoceno temprano (Daniano).

\section{DISCUSIÓN}

\section{Implicaciones estratigráficas}

Todos los depósitos hemipelágicos estudiados, sin excepción, contienen una fauna de foraminíferos planctónicos del Daniano (Fig. 6). Considerando el hecho de que los afloramientos estudiados en Quepos se sitúan cerca del contacto entre el basamento y la cobertura sedimentaria (Fig. 2), la fauna cretácica de foraminíferos planctónicos identificada en las calizas y tobitas hemipelágicas de Quepos indica que la edad Paleoceno temprano es la edad mínima del complejo básico. De particular importancia estratigráfica es la presencia de ejemplares de Gansserina gansseri (Bolli) en tres de las cuatro localidades estudiadas, pues esta especie guía podría señalar una edad máxima maastrichtiana tardía para el Complejo de Quepos (Fig. 6). Estratigráficamente, esto sugiere que las rocas expuestas del Paleoceno inferior podrían representar la unidad más

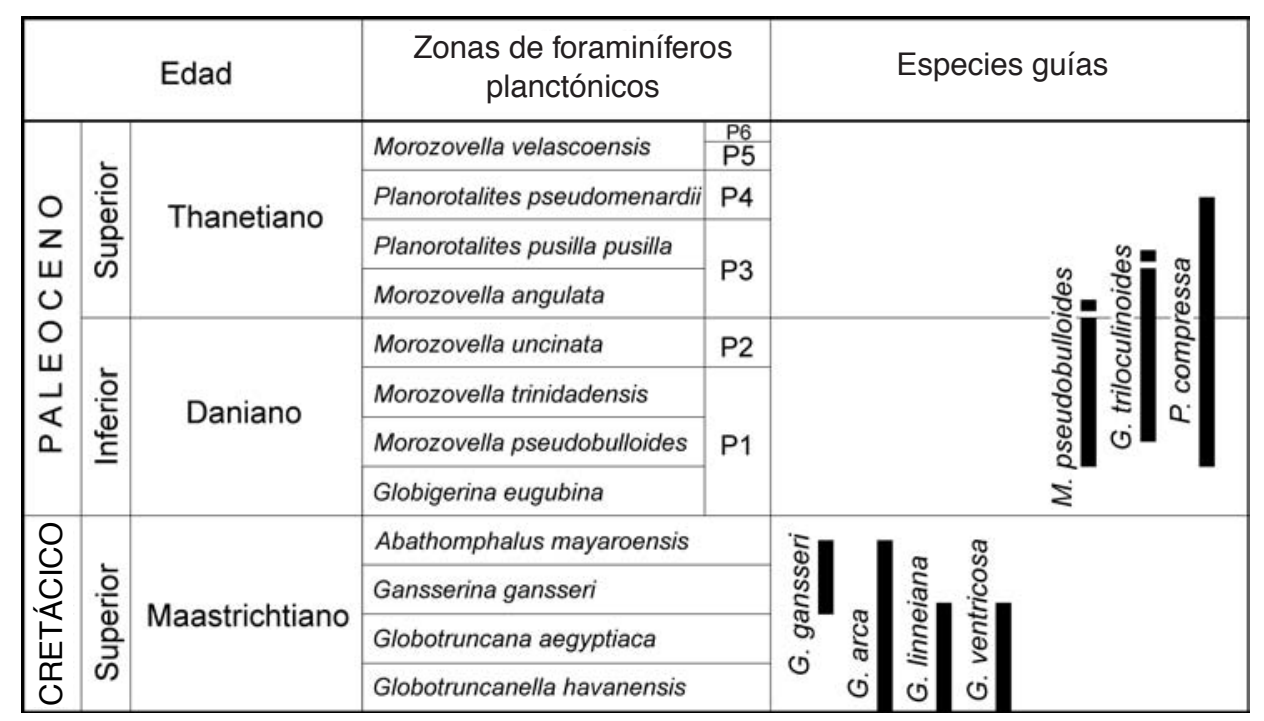

Fig. 6: Distribución bioestratigráfica de las especies de foraminíferos planctónicos identificadas en los depósitos hemipelágicos del basamento de Quepos, río Cañas (fila Chonta) y quebrada Palma (Parrita). Las muestras de los nuevos depósitos estudiados, incluyendo las infiltraciones en basaltos de quebrada Sucia contienen una asociación común de foraminíferos del Daniano. Las calizas y tobitas hemipelágicas de Quepos exhiben además una fauna accesoria de formas retrabajadas del Cretácico Tardío -Maastrichtiano. Biozonación y rangos estratigráficos de las especies guías según Caron (1985) y Toumarkine \& Luterbacher (1985). 
jóven del Complejo Básico de Quepos, la cual sobreyacería directamente la unidad inmediata más antigua, es decir una unidad maastrichtiana. Calizas maastrichtianas de la biofacies de G. gansseri afloran en diferentes localidades del basamento cretácico de Costa Rica, generalmente asociadas con lavas y brechas basálticas, por ejemplo en puerto Carrillo, península de Nicoya (Schmidt-Effing, 1979) y en el sector de Golfito (Di Marco, 1994) (Fig. 1B). Por otro lado, la asociación daniana de foraminíferos planctónicos identificada en las infiltraciones sedimentarias de los basaltos de quebrada Sucia, situada en el flanco sureste de fila Chonta, y en quebrada Palma, al norte de Parrita permite correlacionar la facies hemipelágica de ambas localidades con las calizas danianas del basamento de Quepos. Todas ellas se depositaron en el Paleoceno temprano durante la actividad volcánica submarina que dió origen al Complejo Básico de Quepos.

\section{Sedimentología}

La abundancia de foraminíferos planctónicos en las calizas y tobitas del Complejo de Quepos así como la restringuida extensión lateral de estos materiales indican que se trata de sedimentos hemipelágicos depositados sobre un substrato irregular, producto de la actividad volcánica submarina en la región antearco. La presencia de laminación paralela en algunas muestras estudiadas, marcada por la alternancia de niveles de wackestones y packstones con matriz micrítica en las calizas y la alternancia de niveles vítreos con soporte de grano y niveles con matriz arcillosa en las tobitas, señala el predominio de una sedimentación hemipelágica por caída de partículas biogénicas y también piroclásticas, seguida de una resedimentación local por corrientes laminares tenues, probablemente turbidíticas. Los materiales piroclásticos de puerto Escondido indican que la sedimentación hemipelágica tuvo lugar bajo una actividad volcánica explosiva. La ausencia de fenómenos de alteración metamórfica en la zona de contacto entre caliza y basalto en los afloramientos estudiados de punta Quepos, puerto Escondido y quebrada Camaronera favorecen la depositación e infiltración de sedimento hemipelágico sobre y entre los flujos de lavas frías, respectivamente. No obstante, Gursky (1989, p. 48) describe un canto rodado de basalto vesicular del sur de punta Quepos con inclusiones de caliza rosada (xenolitos) mostrando bordes metamorfizados que no deja descartar una actividad volcánica relativamente contemporánea con la depositación de las calizas y brechas paleocenas, como se observa en algunas infiltraciones sedimentarias de los basaltos vesiculares de quebrada Sucia y quebrada Palma. En este caso, el sedimento hemipelágico infiltró rápidamente en vesiculas y también a través de fracturas hasta alcanzar niveles aún calientes de las lavas, dando origen a contactos metamórficos locales. El mecanismo de formación de estas infiltraciones puede estar asociado también con la injección de sedimento hemipelágico por causa de la sobrecarga que produce el desplazamiento de flujos de lava basáltica sobre un substrato blando. En los afloramientos de quebrada Palma hay evidencia de que los flujos basálticos penetraron incluso los sedimentos hemipelágicos.

\section{Origen del Complejo de Quepos}

Como se deduce de la asociación de materiales volcánicos y sedimentarios, compuesta de lavas vesiculares y brechas basálticas, tobitas vítreas y calizas hemipelágicas, el Complejo de Quepos representa una secuencia volcánica que se formó por la extrusión de magma basáltico en un ambiente submarino a una profundidad tanto por encima de la CCD (profundidad de disolución de carbonatos) como de la profundidad de formación de vesiculas en lavas basálticas ( $<1000$ m cf. Moore, 1975) (Fig. 7). En especial, la alternancia de brechas basálticas y sedimentos hemipelágicos finos de esta secuencia marca la existencia de escarpes submarinos relacionados con un fuerte relieve volcánico, producto de la actividad basáltica durante el Paleoceno temprano, y probablemente Maastrichtiano en el área del antearco (Fig. 7). Por otro lado, los materiales piroclásticos de 
puerto Escondido documentan la coexistencia de un vulcanismo explosivo en el arco interno. En particular, la predominancia de fragmentos vesiculares y esquirlas de paredes de vesículas de vidrio volcánico diferenciado en las tobitas muestra que el vidrio volcánico se formó por causa de fuertes explosiones volcánicas, es decir, por la fragmentación piroclástica subaérea de un magma mucho más diferenciado. La presencia de clastos de calizas someras con macroforaminíferos del Cretácico Tardío en Quepos (Azéma et al., 1979) señala en efecto que estas áreas submarinas estuvieron conectadas con regiones cretácicas emergidas del arco, al igual que en la península de Nicoya.

La relación genética entre el Complejo de Quepos y el de Nicoya se refleja en la composición química de los basaltos, pues a pesar del carácter alcalino de las lavas de Quepos, Sinton et al. (1997) concluyen con base en el análisis isotópico de elementos químicos que ambos provienen de un magma similar. Cabe destacar que la presencia de basaltos alcalinos no es exclusiva de secuencias volcánicas de islas oceánicas, sino que este tipo de roca se encuentra también en secuencias de arcos de islas. Otra característica importante en común es la bimodalidad composicional de materiales volcánicos básicos y piroclásticos diferenciados presente en el Complejo de Nicoya (Calvo \& Bolz, 1994) y ahora determinada también en Quepos con el hallazgo de las tobitas vítreas de puerto Escondido. Esa marcada bimodalidad composicional es característica de secuencias de arco de islas intraoceánicos (Calvo, 1998; Schmincke, 2000).

Desde el punto de vista tectónico, la ausencia de estructuras de acreción, que muestran la cartografía a escala 1:10 000 del promontorio de Quepos realizada por la Universidad de Costa Rica en 1982 y los estudios de sísmica de

A) Paleoceno temprano (vulcanismo basáltico emergente)

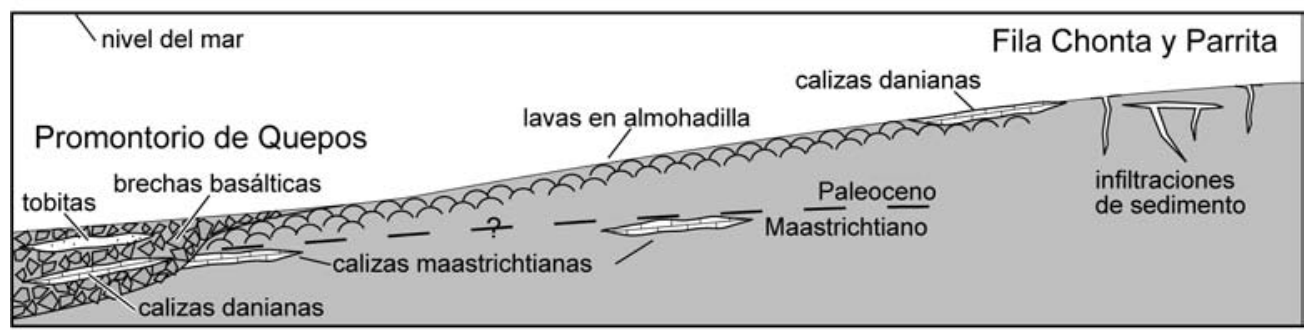

B) Paleoceno tardio: levantamiento tectónico (zona de Ranikothalia bermudezi)

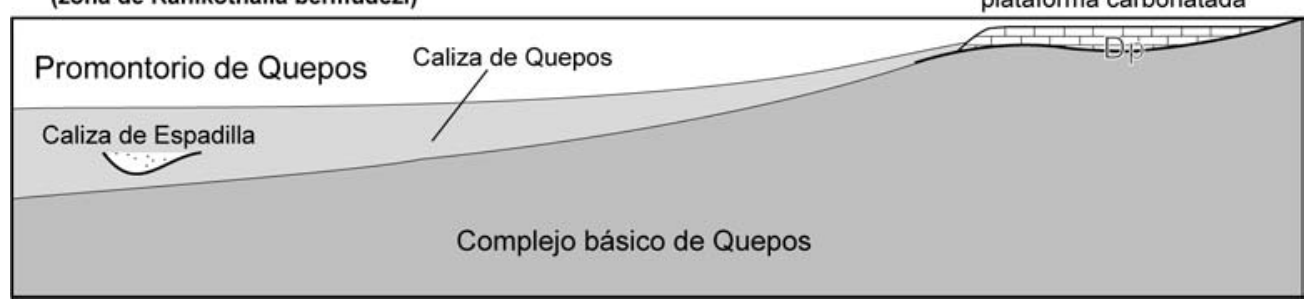

Fig. 7: Modelo de formación del Complejo Básico de Quepos por causa de la actividad volcánica submarina en la región antearco pacífica de Costa Rica durante el Paleoceno temprano y probablemente Maastrichtiano (A). El vulcanismo basáltico estuvo acompañado de una sedimentación hemipelágica carbonatada y piroclástica. Las texturas vesiculares comunes de los basaltos y tobas palagoníticas indican una profundidad de formación del basamento en esa región menor de $1000 \mathrm{~m}$ hasta marina somera. De este modo, el complejo básico formó probablemente parte del flanco de un aparato volcánico emergente o isla volcánica. En el Paleoceno tardío (B), el levantamiento tectónico del antearco causó la emersión de ese complejo, seguida de la depositación discordante de calizas de plataforma en el retropaís (fila Chonta) así como de la depositación de las calizas hemipelágicas de Quepos y las alodápicas de Espadilla en el área del promontorio de Quepos. Dp: discordancia paleocena. 
reflexión (Barboza \& Zucchi, 1994; Hinz et al., 1996), documenta el carácter autóctono del basamento ofiolítico de Quepos. Tanto la ausencia de estructuras de acreción como las asociaciones de foraminíferos cretácicos y la prolongación del complejo hacia el retropaís son argumentos concluyentes en contra de la teoría de un complejo paleoceno acrecionado en Quepos.

\section{Basamento de fila Chonta y Parrita}

Como demuestran las infiltraciones de sedimento hemipelágico y las texturas vesiculares en los basaltos de quebrada Sucia, el basamento del flanco sureste de fila Chonta se formó por causa de una actividad basáltica submarina, emergente en el Paleoceno temprano, contemporánea con la del promontorio de Quepos (Fig. 7). Aparentemente, este basamento constituyó el substrato volcánico sobre el cual se desarrolló la secuencia transgresiva de calizas de plataforma de Ranikothalia bermudezi en el Paleoceno tardío (Calvo \& Bolz, 1991). Las observaciones realizadas en el área de la quebrada Palma señalan de forma similar la extensión del basamento paleoceno hacia el oeste, hasta la cuenca de Parrita (Fig. 7). No obstante, la prolongación del basamento cretácico de Herradura hacia esta región, que deducimos de nuestras observaciones de campo, así como la presencia de calizas cretácicas con macroforaminíferos en las brechas basálticas de Quepos (Azéma et al, 1979) sugieren también la probable existencia de rocas basálticas cretácicas tanto en Parrita como en fila Chonta.

\section{CONCLUSIONES}

Identificamos una serie de nuevos afloramientos del Paleoceno inferior de rocas sedimentarias hemipelágicas del basamento de la región antearco central de Costa Rica, que se atribuyen al Complejo Básico de Quepos. En tres de los cuatro nuevos afloramientos de calizas y tobitas vítreas danianas del promontorio de Quepos identificamos una asociación alóctona de foraminíferos planctónicos del Cretácico Tardío, constituída por ejemplares con quilla de las especies: Rosita sp., Globotruncana f. arca (Cushman), Globotruncana cf. ventricosa (White), Globotruncana cf. linneiana (d'Orbigny), Globotruncanella sp. y Gansserina gansseri (Bolli). Esta asociación, en especial la presencia de G. gansseri (Bolli), especie guía del Maastrichtiano tardío, en tres de las localidades estudiadas sugiere la probable existencia de rocas cretácicas maastrichtianas en los niveles inferiores inmediatos de ese complejo.

La asociación cretácica de foraminíferos planctónicos así como la afinidad geoquímica y litológica entre las lavas de Nicoya, Herradura y Quepos en conjunto con la ausencia de estructuras de accreción en esa región indican que el Complejo de Quepos constituye parte de la secuencia ofiolítica antearco de Costa Rica, formada in situ por la extrusión de material basáltico en el Paleoceno temprano y probablemente Maastrichtiano. En particular, las tobitas de puerto Escondido registran una actividad explosiva paleocena que tuvo lugar en el arco interno y que fue contemporánea con la actividad submarina basáltica propiamente dicha. Esos materiales documentan la bimodalidad composicional de productos volcánicos característica de arcos de islas intraoceánicos e identificada previamente en la península de Nicoya.

Los afloramientos paleocenos de rocas basálticas del área del río Cañas y quebrada Palma indican además que el Complejo de Quepos se prolonga hasta la región montañosa del retropaís llegando a formar parte del basamento antearco de fila Chonta y de la cuenca de Parrita. Sobre ese basamento daniano levantado transgredieron discordantemente las calizas neríticas de la facies de Ranikothalia bermudezi en el Paleoceno tardío.

Paleogeográficamente, las secuencias del basamento de Quepos, fila Chonta y Parrita forman parte del flanco de un aparato volcánico emergente - una isla volcánica- producto de actividad basáltica en la región antearco de Costa Rica durante el Paleoceno temprano y probablemente Maastrichtiano. 


\section{AGRADECIMIENTOS}

Discusiones con H-P. Luterbacher (Tübingen) sobre las asociaciones de foraminíferos analizadas fueron muy útiles. Agradecemos también a M. Meschede (Greifswald) y W. Frisch (Tübingen) por su ayuda durante el estudio microscópico.

\section{REFERENCIAS}

AZÉMA, J., GLAÇON, J., TOURNON, J. \& VILA, J.-M., 1979: Precisiones acerca del Paleoceno de puerto Quepos y sus alrededores, provincia de Puntarenas, Costa Rica. - Inst. Geogr. Nac. Inf. II: 77-88.

BARBOZA, G. \& ZUCCHI, H., 1994: Sismoestratigrafía de algunas cuencas en el antearco del sector central de Costa Rica. Profil, 7: 161-169.

BAUMGARTNER, P.O, MORA, C. R., BUTTERLIN, J., SIGAL, J., GLAÇON, G., AZÉMA, J. \& BOURGOIS, J., 1984: Sedimentación y paleogeografía del Cretácico y Cenozoico del litoral Pacífico de Costa Rica. - Rev. Geol. América Central, 1: 57-136.

BECKER, R., 1991: Die Entwicklungsgeschichte des östlichen Parrita-Beckens im Tertiären „Forearc"-Bereich der südlichen Zentralamerikanischen Landbrücke (Costa Rica). - 92 págs. Univ. de Maguncia, Maguncia [Tesis Diplom.]

CALVO, C., 1998: Kretazische Subduktionsprozesse in Südzentralamerika. - Profil, 15: $1-161$.

CALVO, C. \& BOLZ, A., 1991: La Formación Espíritu Santo (Costa Rica): Sistemas de plataforma carbonatada autóctona del Paleoceno Superior-Eoceno Inferior. - Rev. Geol. América Central, 13: 91-95.
CALVO, C. \& BOLZ, A., 1994: Der älteste Inselbogen-Vulkanismus in Costa Rica. Marine Pyroklastika der Formation Loma Chumico (Alb bis Campan). - Profil, 7: 235-264.

CARON, M., 1985: Cretaceous planktic Foraminifera. - En: Bolli, H. M., Saunders, J. B. \& Perch-Nielsen, K. (eds.): Cambridge Earth Sciencie Series-Plankton Stratigraphy. Cambridge Univ. Press, 1: 17-86.

DENGO, G., 1985: Mid America: Tectonic setting for the Pacific margin from southern Mexico to northwestern Colombia. - En: Nairn, A. E. M., Stehli, F. G. \& Uyeda, S. (eds.): The oceans margins and basins. Plenum Press, New York, 7: 123-180.

DI MARCO, G., 1994: Les terrains accrétés du Sud Costa Rica - Evolution tectonostratigraphique de la marge occidentale de la plaque Caribe. - 183 págs. Univ. de Lausanne, Lausanne [Tesis Ph.D.]

HINZ, K., VON HUENE, R. \& RANERO, C.R., 1996: Tectonic structure of the convergent Pacific margin offshore Costa Rica from multichannel seismic reflection data. Tectonics, 115: 54-66.

GURSKY, H.-J., 1989: Presencia y origen de rocas sedimentarias en el basamento ofiolítico de Costa Rica. - Rev. Geól. América Central, 10: 19-66.

MESCHEDE, M. \& FRISCH, W., 1994: Geochemical characteristics of basaltic rocks from the Central America ophiolites. Profil, 7: 71-86.

MOORE, J. G., 1975: Mechanism of formation of pillow lava. - Am. Sci., 63: 269-277.

SCHMIDT-EFFING, R., 1979: Alter und Genese des Nicoya-Komplexes, einer ozeanischen Paläokruste (Oberjura-Eozän) im 
südlichen Zentralamerika. - Geol. Rundschau, 68: 457-494.

SCHMINCKE, H.-U., 2000: Vulkanismus. - 264 págs. Wissenschaftliche Buchgesellschaft, Darmstadt.

SINTON, C.W., DUNCAN, R.A. \& DENYER, P., 1997: Nicoya Peninsula, Costa Rica: A single suite of Caribbean oceanic plateau magmas. - J. Geophys. Res. 102: 15,50715,520 .
TOUMARKINE \& LUTERBACHER, H.-P., 1985: Paleocene and Eocene planktic Foraminifera. - En: Bolli, H. M., Saunders, J. B. \& Perch-Nielsen, K. (eds.): Cambridge Earth Sciencie Series-Plankton Stratigraphy. Cambridge Univ. Press, 1: 87-154.

WILDBERG, H., 1984: Der Nicoya-Komplex, Costa Rica, Zentralamerika: Magmatismus und Genese eines polygenetischen Ophiolith-Komplexes. - Münster. Forsch. Paläont. 62: 1-123. 